\title{
A New Beginning
}

As I imagine you have noticed, the journal you hold in your hands or on your monitor has changed. At the very least, you will have noticed that the journal has a new name, Attention, Perception, \& Psychophysics. It has a new editorial board, new features, and a renewed commitment to publish the best science in our field. As the new editor, it falls to me to say a few words about all of this.

\section{$P \& P$ Gets an $A$}

First, the name of the journal: Why change after all these years? The new title reflects the evolution of the contents. As the field of attention grew over the last 20 years, its representation in $P \& P$ grew too. In $1988,5 \%$ of $P \& P$ articles were attention articles. In 2008 , that number was close to $50 \%$. Moreover, there is no other major journal with attention in its title. In making this change, we announce our intention to be the leading outlet for attention research while maintaining our strong commitment to publish the best in perception and psychophysics.

\section{What Will We Publish?}

Tutorials. In each issue (starting with the next issue), there will be a tutorial on some basic topic in attention, perception, and/or psychophysics. Our goal is to amass a series of articles that will be the first place to look if you want to know about X.

Brief Reports. There is a place for clever new findings that can be quickly communicated to specialists in the trade. Unlike Science or Nature, we would not expect that our brief reports would speak to everyone from social psychologists to cellular neurobiologists. We expect that these will describe something striking and new for our community.

News From the Field. In each issue, we will publish a page or two of brief descriptions of interesting articles from outside of the pages of $A P \& P$.

Research Articles. Our primary mission will remain the publication of scholarly articles in attention, perception, and psychophysics. Most of these will be empirical in nature, but, perhaps more than in the past, we encourage empirically grounded models and theories. We are eager to publish the package of three or four experiments that test a hypothesis. We are also eager to publish the theory based on a body of empirical work.

\section{How Will We Publish?}

Faster. Our time to review papers is down. The lag from acceptance to publication is down. As editors, we are committed to bringing the review time down even further and we know that the production folks are committed to getting the accepted papers into print as fast as possible.

Electronically. The journal's new electronic home, http://app.psychonomic-journals.org/, is a substantial improvement and will get better over time. Take a moment now to register to get AP\&P's table of contents delivered by email as soon as a new issue is available.

Colorfully. Full color illustrations can now be placed in the pdf version of articles for a nominal fee. We encourage authors to let readers see what the stimuli looked like and to take advantage of color to clarify the presentation data.

\section{What Do We Want From You?}

Your best work. We want the first "big" paper from your thesis. We want the definitive statement of your theory. We want the experiments that will transform the field.

Your self-nominations. We will solicit tutorials but if you are The Expert on a topic (or even one of the experts), we would be delighted to hear from you. Tutorials are invited submissions but please invite us to invite you. Similarly, if you read something outside of $A P \& P$ that should be described in the News From the Field section, drop us a note offering to write a couple of paragraphs.

Your reviews. Reviews are the lifeblood of a journal. If we are to publish the best, we need intelligent reviews from willing reviewers. If we are to publish quickly, we need reviewers who return reviews in a timely fashion. Reviewing is a debt we owe the field.

Your comments. Tell us how we are doing. Tell us what we should be doing. My e-mail iswolfe@ search.bwh.harvard.edu. 